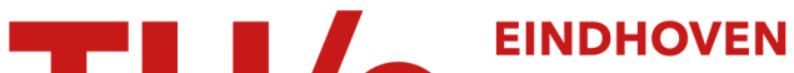 \\ UNIVERSITY OF \\ TECHNOLOGY
}

\section{Scale-up of chaotic fluidized bed hydrodynamics}

\section{Citation for published version (APA):}

Schouten, J. C., Stappen, van der, M. L. M., \& Bleek, van den, C. M. (1996). Scale-up of chaotic fluidized bed hydrodynamics. Chemical Engineering Science, 51(10), 1991-2000. https://doi.org/10.1016/0009-

2509\%2896\%2900056-5, https://doi.org/10.1016/0009-2509(96)00056-5

\section{DOI:}

10.1016/0009-2509\%2896\%2900056-5

10.1016/0009-2509(96)00056-5

\section{Document status and date:}

Published: 01/01/1996

\section{Document Version:}

Publisher's PDF, also known as Version of Record (includes final page, issue and volume numbers)

\section{Please check the document version of this publication:}

- A submitted manuscript is the version of the article upon submission and before peer-review. There can be important differences between the submitted version and the official published version of record. People interested in the research are advised to contact the author for the final version of the publication, or visit the $\mathrm{DOI}$ to the publisher's website.

- The final author version and the galley proof are versions of the publication after peer review.

- The final published version features the final layout of the paper including the volume, issue and page numbers.

Link to publication

\section{General rights}

Copyright and moral rights for the publications made accessible in the public portal are retained by the authors and/or other copyright owners and it is a condition of accessing publications that users recognise and abide by the legal requirements associated with these rights.

- Users may download and print one copy of any publication from the public portal for the purpose of private study or research.

- You may not further distribute the material or use it for any profit-making activity or commercial gain

- You may freely distribute the URL identifying the publication in the public portal.

If the publication is distributed under the terms of Article 25fa of the Dutch Copyright Act, indicated by the "Taverne" license above, please follow below link for the End User Agreement:

www.tue.nl/taverne

Take down policy

If you believe that this document breaches copyright please contact us at:

openaccess@tue.nl

providing details and we will investigate your claim. 


\title{
SCALE-UP OF CHAOTIC FLUIDIZED BED HYDRODYNAMICS
}

\author{
J.C. SCHOUTEN, M.L.M. VANDER STAPPEN' ${ }^{\prime}$ and C.M. VAN DEN BLEEK
}

Delft University of Technology, Faculty of Chemical Technology and Materials Science,

Chemical Reactor Engineering Section, Julianalaan 136, 2628 BL Delft, The Netherlands

\begin{abstract}
This paper focuses on scale-up of the dynamic behavior of gas-solids fluidized bubbling reactors. An empirical approach is followed that is based on the observation that the non-linear, hydrodynamic behavior of bubbling fluidized beds is of a chaotic nature. The degree of chaos is quantified by the Kolmogorov entropy, which is a measure of the rate of loss of information in the system (expressed in bits of information per second). The basic idea of the 'chaos scale-up methodology" proposed in this paper is that the rate of information loss should be kept similar when scaling up a bubbling bed from the small scale to the larger scale, in order to ensure dynamic (i.e. chaotic) similarity between the scaled beds. For a set of Geldart-B and -D particle systems, and for a range of bed diameters (from $0.1 \mathrm{~m}$ ID up to $0.8 \mathrm{~m}$ ID), an empirical correlation (Equation 4 in the paper) is derived that relates Kolmogorov entropy to main bubbling bed design parameters, viz. (i) fluidization conditions (superficial gas velocity, settled bed height), (ii) particle properties (minimum fluidization velocity), and (iii) bed size (diameter). It is illustrated by numerical examples how this correlation might be used in scaling up the chaotic dynamics of bubbling fluidized reactors. It is further shown that a similar type of correlation for Kolmogorov entropy can also be derived theoretically (Equations 1 and 5 in the paper).
\end{abstract}

\section{INTRODUCTION AND BACKGROUND}

Fluidized bed reactors are among the most important reactors in the chemical industry, because they offer excellent possibilities for dealing with reactants in gas/solid/liquid, exo- and endothermic reaction systems. By nature, gassolids fluidized beds have good particle mixing, high heat and mass transfer rates as well as a low pressure drop. However, due to the complexity of the hydrodynamics, design and scale-up of this type of chemical reactor are still difficult and often considered to be more an 'art' than 'science'. For example, the influence of the reactor size on the fluid dynamic regimes and their transitions is not yet fundamentally well understood.

At Delft University of Technology a comprehensive programme of research is carried out since 1990 with the idea of developing a chaos scale-up methodology using empirical correlations that relate the chaotic dynamics to reactor size and operating conditions. In this empirical approach pressure fluctuation information is used to reveal and quantify effects of scale-up in fluidized beds. This simple technique enables measurements at commercial fluidized beds, hence verification of scale-up rules beyond present laboratory scales.

\section{Fluidized bed hydrodynamics}

The hydrodynamical behavior of gas-solids fluidized bed reactors is very complex. The particles are suspended in the upward moving gas and gas in excess of the minimum fluidization velocity (partly) passes the bed in the form of bubbles. Overall, the solids are well mixed, primarily by the bubble induced particle motion. The dynamical regime of a fluidized bed depends, among others, on the type of particles, the superficial gas velocity, the bed height (or total mass of particles), and the bed diameter. Moreover, special designs depending on the application, such as internals, solids feed and/or off-take, and the distributor influence the hydrodynamics and thus reactor performance (Werther, 1992). In this paper, the hydrodynamics of stationary beds (i.e. no solids carry over as in high velocity circulating fluidized beds) in the bubbling and slugging regime are studied, primarily of Geldart type B particles. In these types of beds, the hydrodynamical behavior is clearly governed by the time dependent behavior of the bubbles, i.e. their (initial) size, growth and coalescence rates, and rise velocities.

\section{Characterization of fluidized bed hydrodynamics: Chaos analysis}

Usually, fluidized bed hydrodynamics are characterized using time-averaged properties, such as the average bubble diameter and rise velocity or the average bubble holdup and bed voidage. This approach neglects the time dependent dynamical behavior that is considered to be important for the performance of the fluidized bed. When, for example, pressure (drop) or voidage at a certain position in the bed is measured, it is found to oscillate considerably and

\footnotetext{
${ }^{1}$ Presently with Unilever Research Laboratory, Vlaardingen, The Netherlands
} 
highly irregularly. Traditionally, in fluidization engineering, time series of fluctuations of pressure or voidage are analyzed using statistical (e.g. averages, standard deviation) or spectral (e.g. Fourier transform, power spectrum or autocorrelation function) analysis. Implicitely, these analysis techniques assume that the oscillations can be described by a linear summation of random variations, or by a linear addition of different periodic waves, respectively. Stringer (1989), however, was the first to suggest that the irregular, aperiodic behavior of the fluidized bed's dynamics is due to the fact that it is a non-linear, chaotic system. For that reason, it seems appropriate to analyze time-dependent fluidized bed data with specific techniques that take account of the aperiodicity and nonlinearity of the dynamics. This is what is called chaos analysis, in comparison to statistical analysis and spectral analysis.

\section{Quantifying chaotic systems: the Kolmogorov entropy}

Chaotic systems are governed by non-linear interactions between the system variables. Due to this non-linearity, these deterministic systems are sensitive to small changes in initial conditions and are, therefore, characterized by a limited predictability. In other words, information about the initial state of the system is lost when it evolves in time. The chaotic dynamics of a system are fully represented by its attractor in the phase space, which describes the time evolution of the system and which can be quantified by characteristic invariants. These chaos characteristics of dynamical systems can be estimated from time series of only one of the system's characteristic variables, such as pressure fluctuations in bubbling gas-solids fluidized beds, via a technique called (attractor) reconstruction (Takens, 1981). One of the most important chaos characteristics is the Kolmogorov entropy which measures the rate of loss of information (expressed in bits of information per unit of time), and which quantifies the limited predictability of chaotic systems. In general, Kolmogorov entropy is large for very irregular dynamic behavior (like pressure fluctuations in turbulent gas flow), while it is small in case of more regular, periodic-like, lower dimensional behavior (like in slugging beds). The limiting values for Kolmogorov entropy are infinity for complete random systems (infinite information loss), and zero for completely periodic systems (in which no information is lost during evolution of the system, because next states can be completely and accurately predicted from previous ones). A practical maximum-likelihood method to estimate Kolmogorov entropy from (measured) time series has been reported by Schouten et al .(1994a). Also many textbooks have appeared in the literature that give a general introduction on chaos theory and chaos analysis techniques; for example Moon (1992) and Hilborn (1994).

\section{PREVIOUS WORK ON CHAOS ANALYSIS OF BUBBLING GAS-SOLIDS FLUIDIZED BEDS}

Since Stringer's suggestion (1989), a number of articles relating chaos to fluidized beds have appeared. Most of this work related to gas-solids fluidized beds has been done centred around two research groups, one at Oak Ridge National Laboratory (ORNL, USA) and one at the authors' group at Delft University of Technology (DUT, The Netherlands). A number of possibilities to practically apply chaos analysis of fluidized hydrodynamics have been identified in various papers. These are outlined now, followed by a review of work that has been done on bubbling fluidized beds.

\section{Use of chaos analysis for fluidized beds}

The analysis tools from chaos theory offer unique measures to quantitatively characterize the complex hydrodynamical behavior of fluidized beds. Especially the Kolmogorov entropy (simply called entropy in the remainder of this paper) has been found to be a sensitive, robust and very characteristic invariant for the dynamics that can be readily calculated from measured time series of, for example, pressure fluctuations in the bed. Chaos analysis can be applied in fluidized bed design, scale-up, control, and to increase fundamental understanding of the hydrodynamics. First of all, chaos invariants uniquely quantify the hydrodynamics and therefore they can be used to assess which operating variables influence the dynamics and how strongly they do so. When fluidized beds are analyzed using the same standardized method, chaos analysis can be applied for quantitative comparison; not only between various operating conditions (in the same or different beds), or between two scaled beds to assess dynamic similarity, but also between experiments and dynamic model simulations. Moreover, differences between dynamic fluidization regimes and their transitions can be quantitatively identified.

Earlier experimental work demonstrated the chaotic characteristics from pressure fluctuation data, and showed that these varied with operating conditions and position in the bed (e.g. Daw and Halow, 1991; Daw et al., 1990; Fuller et al., 1993; Hay et al., 1995; Schouten and Van den Bleek; 1991, Schouten et al. 1992; Skrzycke et al., 1993; Vander Stappen et al., 1993b). Simple hydrodynamic modelling to mimick the chaotic behavior has been done by Daw and Halow (1992) and Schouten and Van den Bleek (1992). The latter model was able to describe the trends in the chaos invariants as they are measured at the transition from a fixed to a bubbling bed (Vander Stappen $e t$ al., 1993a). Typically, it is observed that the states preceeding the freely bubbling regime in the experiments as well as the corresponding freely oscillation of the particles in the model, are quantified by a low entropy, indicating a kind of reordering of the gas-solids system before it developes to a new and dynamically more complex regime. 
Schouten, 1993b; Daw and Halow, 1993; Halow and Daw, 1994). Van den Bleek and Schouten (1993a) argue that in the scaling of fluidized beds, the information flow or entropy on a normalized time scale should be kept constant. Scale-up forms the main goal of the work at Delft University sofar. More recently, control strategies based on the non-linear properties of a chaotic system have been proposed (Ott et al., 1991), which are now also explored for their use on fluidized beds (Vasudevan et al., 1995; De Korte et al., 1995).

Especially in the earlier work, various methods have been tried to calculate the chaos invariants from experimental time series. Practical methods that can deal with (noise contaminated) measured data have been developed by Schouten et al. (1994a, 1994b), together with practical guidelines to analyze each time series in a standardized way. These techniques are largely followed in recent work. Tools to specifically study the spatio-temporal characteristics of the dynamics of a fluidized bed have also been proposed (Vander Stappen et al., 1994).

\section{SCOPE OF THIS PAPER}

Sofar, literature data almost only showed measured trends of the chaos invariants as a function of the operating variables. Interpretation was, at best, done qualitatively in terms of overall fluidized bed behavior (visually observed). The first empirical correlation for the entropy was presented in Van den Bleek and Schouten (1993b). Vander Stappen et al. (1995) were the first to present a model-based interpretation of measured entropies in terms of the bubble flow properties. Entropy data from one type of Geldart-B particles in beds up to $0.38 \mathrm{~m}$ ID, measured in the centre of the column, were described well over a wide range of operating conditions.

Here, the concepts of using the entropy as a tool to characterize the hydrodynamics quantitatively and to modelling the measured values using bubble properties that are calculated from existing empirical correlations, are further investigated. New data, from different particle systems and from beds up to $0.8 \mathrm{~m}$ ID, are discussed. The issue of representativity of pressure measurements in large beds is addressed. Also, the engineering correlations that relate entropy to bed size and fluidization conditions, are compared to results from a separate experiment in which two beds, scaled according to Glicksman's similarity rules (Glicksman et al., 1994), are analyzed using chaos analysis. Finally, in the section 'Scale-Up' at the end of this paper, it is discussed how all these results fit together in the development of a chaos scale-up methodology for the hydrodynamics of bubbling gas-solids fluidized beds. The basic idea of this scale-up methodology is that the rate of information loss, as expressed in the Kolmogorov entropy, should be kept similar when scaling up a fluidized bed to obtain dynamical (viz.chaotic) similarity.

\section{EXPERIMENTAL CONDITIONS}

All experiments described in this paper have been done in cold scale models of fluidized beds using air at ambient conditions as the fluidizing gas. The bed diameter varies from 0.1 to $0.8 \mathrm{~m}$ ID. Various particle systems have been used, but most data are from two different particle systems, whose properties are given in Table 1 .

\begin{tabular}{||c|c|c:c|c|c|c|}
\hline Material & $\rho_{\mathrm{p}}\left(\mathrm{kg} / \mathrm{m}^{3}\right)$ & $\bar{d}_{p}(\mathrm{~mm})$ & $d_{10} / d_{90}(\mathrm{~mm})$ & $U_{\mathrm{mf}}(\mathrm{m} / \mathrm{s})$ & Geldart type & Shape \\
\hline Polystyrene & 1102 & 0.56 & $0.49 / 0.62$ & 0.14 & $\mathrm{~B}$ & sperical \\
Sand & 2640 & 0.40 & $0.32 / 0.41$ & 0.14 & $\mathrm{~B}$ & angular \\
\hline
\end{tabular}

Table 1: Propertics of the two most used particle systems. The values of $U_{\mathrm{m}}$ have been determined from pressure drop experiments

Porous sintered bronze plates ( $30 \mu \mathrm{m}$ pore size) have been used in all beds. Pressure fluctuation time series have been used to calculate entropies in all cases, measured using a piezo-electric type of sensor (Kistler type 7261) with a lowest accuracy of about $1 \mathrm{~Pa}$. The time series consisted of at least 65,536 points (most often twice this number) and were sampled at frequencies between 100 and $700 \mathrm{~Hz}$, depending on the operating conditions, according to the standard measurement and analysis procedure referred to above. Analog low-pass filtering at $60 \mathrm{~Hz}(40 \mathrm{~Hz}$ for sample frequencies below $150 \mathrm{~Hz}$ ) was always applied before the 16 bits ADC. The pressure tubes were tested to have no significant influence on the response to the pressure fluctuations within the range of 0 to $60 \mathrm{~Hz}$.

\section{DETECTION OF BUBBLE FLOW PATTERNS USING ENTROPY}

Bubble patterns are typically reflected in the measured entropies at different radial and axial positions in the bed (Vander Stappen et al., 1995). There, for a relatively low gas velocity of 2 times $U_{\mathrm{mf}}$ in a bed of $0.56 \mathrm{~mm}$ polystyrene particles, the entropy was measured at the settled bed height in the centre of the column and at the wall; for shallow, intermediate and deep beds (aspect ratio below 1, 1 to 2 and above 2), the entropy in the centre was higher, lower and the same, respectively. This was explained by the change in the preferred bubble pattern from near the walls to the centre for increasingly deeper beds. For high gas velocities, the situation is different and bubbles always rise through the centre in a similar pattern as observed in deep beds (see Kunii and Levenspiel, 1991: chapter 5). In the centre of the bed, the bubbles are sensed most clearly (have the most 'impact') and the entropy is therefore higher or at least equal to the value at the wall. For deeper beds, the bubbles grow larger and 
the differences between the wall and centre dissappear (see Figure 1).

Another example is from the same particles in a shallow bed $\left(H_{\mathrm{s}}=0.22\right.$ $\mathrm{m})$ in a $0.8 \mathrm{~m}$ ID column. A radial profile of the entropy confirms the existence of typical vortex rings with aspect ratio $\sim 1$ (see Figure 2). The entropy is at a maximum at the position where bubbles preferably erupt, i.e. at rougly $0.2 \mathrm{~m}$ from the wall. The examples in Figures 1 and 2 illustrate that the bubble-related hydrodynamics of a fluidized bed are clearly characterized by the entropy. It is also clear that the 'reach' or 'depth of measurement' of a pressure sensor is limited; i.e. a pressure sensor does not measure all bubbles that erupt at the surface, at least not with the same

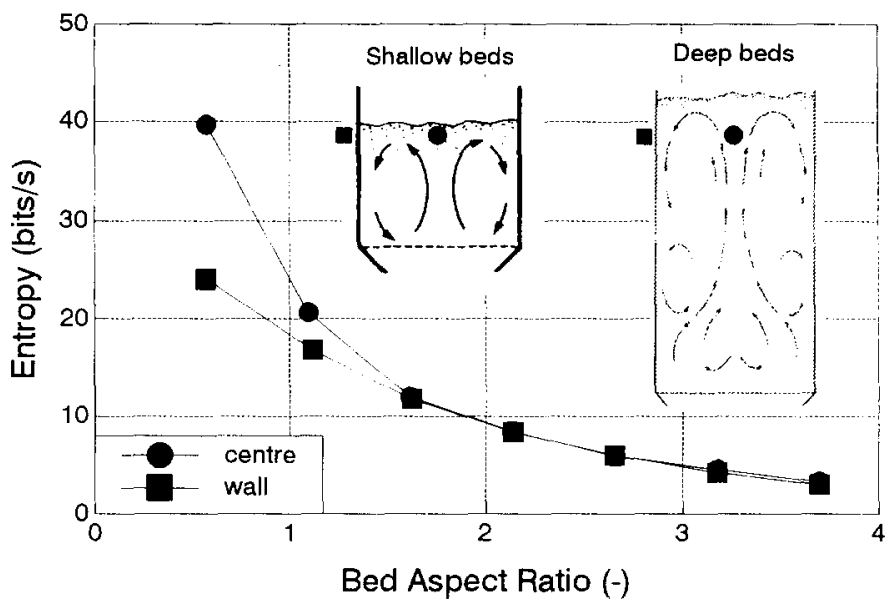

Figure 1: Entropy, measured in the centre and at the wall of the bed at the settled bed height; $0.56 \mathrm{~mm}$ polystyrene particles in a $0.384 \mathrm{~m}$ ID bed; $U_{0}=6 U_{\mathrm{mf}}$. The probe positions are indicated in the schematic bubble patterns (taken from Kunii and Levenspiel, 1991). strength. Local bubbles primarily influence the value of entropy. For large bubbles (compared to the bed diameter) the radial probe position does not matter. In general, the (relative) probe position thus has to be taken into account when different beds and/or different operating conditions are compared. This subject will be discussed more furtheron, as it is a very important result with respect to scaling up to beds that are even much larger (several meters in diameter) than this $0.8 \mathrm{~m}$ ID bed.
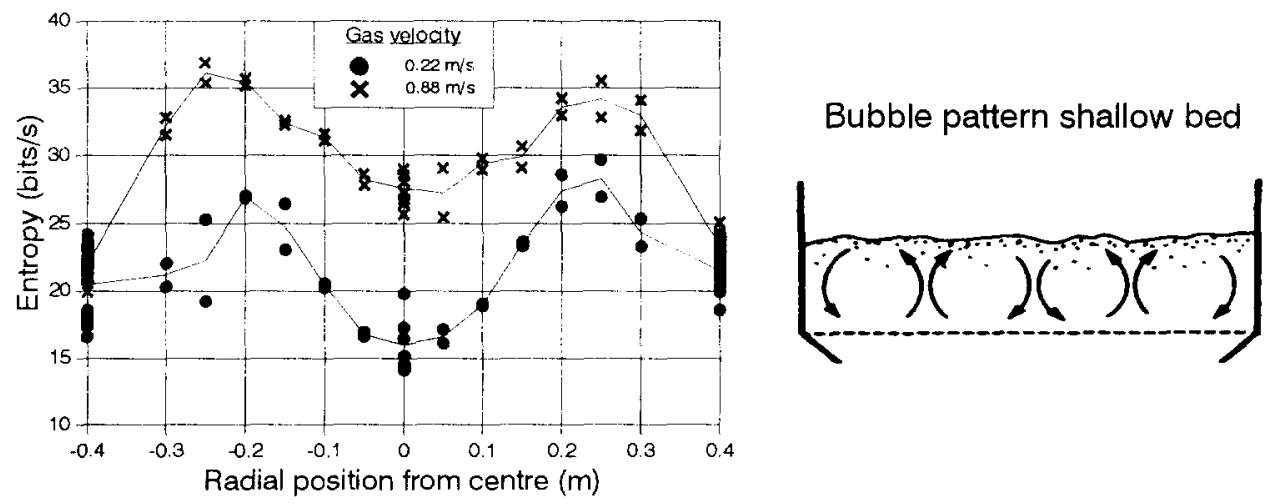

Figure 2: Correspondence between radial pattern in entropy and typical bubble patterns in a shallow bed with porous distributor (taken from Kunii and Levenspiel, 1991). Data from $0.8 \mathrm{~m}$ ID bed; settled bed height $0.22 \mathrm{~m}$; the solid line denotes the average of multiple measurements.

\section{QUANTITATIVE CORRELATIONS AND A MODEL FOR THE ENTROPY}

The discussions here illustrate how chaos analysis may help to better understand fluidized bed hydrodynamics and and to quantitatively compare results from different operating conditions. A more detailed discussion can be found in Vander Stappen (1996).

\section{A model for the entropy}

Measured entropies from the centre of the bed at the settled bed height $(0.56 \mathrm{~mm}$ polystyrene data) have been described, both empirically and using a simple model description (Vander Stappen et al., 1995). Entropy characterizes the rate of information loss of the system. Therefore, in the model. entropy is assumed to be linearly proportional to $(i)$ the total number of bubbles that erupt at the total bed surface per unit of time (representing the rate at which information is lost), multiplied by (i) the bubble impact (a factor that accounts for the amount of information that is represented by one typical bubble). The total number of erupting bubbles per unit area and per unit of time $N$ is found from the excess gas velocity and bubble volume: $N=\phi\left(U_{0}-U_{m f}\right) / V_{B}$, with $\phi=1$ when it is assumed that all excess gas forms bubbles ( $c f$. Darton et al., 1977). Here we take $V_{B}$ based on the equivalent bubble diameter. The bubble impact is simply assumed to be given by the relative bubble size $D_{\mathrm{B}} / D_{\mathrm{T}}$. The result is 


$$
\begin{aligned}
K(\text { bits } / s) \propto \frac{\# \text { bubble eruptions }}{s} * \text { bubble impact } & =N \frac{\pi}{4} D_{T}^{2} *\left(\frac{D_{B}}{D_{T}}\right)=\frac{1.5\left(U_{0}-U_{m f}\right) D_{T}}{D_{B}^{2}} \\
& =19.3\left(U_{0}-U_{m f}\right)^{0.4} \frac{D_{T}}{H_{s}^{1.6}}
\end{aligned}
$$

with $D_{B}=0.44\left(U_{0}-U_{m f}\right)^{0.3} H_{s}^{0.8} g^{-0.2}$. This bubble size equation is found by using Darton $e t$ al.'s (1977) functional relationship for $D_{\mathrm{B}}$ and fitting the parameter values in this relationship to the measured entropy data (using Equation 1). Differences to the original correlation of Darton et al. are typically within $20 \%$.

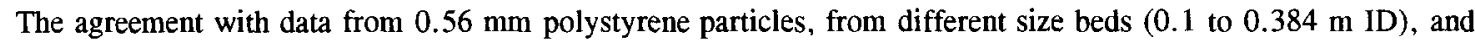
from a wide range of operating conditions is good, as is clear from Figure 3 (in which the constants of Equation 1 are used). Data from shallow beds (aspect ratio < 1) and data close to minimum fluidization are not included; all entropies are measured in the centre of the bed at the settled bed height. Overall, the average deviation of the measured data from the predictions in Figure 3 is $21 \%$. If it is assumed that Equation 1 is correct and that there are no errors in the values of the excess gas velocity and bed diameter, the average error in the estimated bubble size is about $10 \%$, which is acceptable considering the accuracy of typical bubble size correlations.

Also, the same data can be directly fitted to a power-law equation of the independent operating variables:

$$
K=23.5\left(U_{0}-U_{m f}\right)^{0.4} \frac{D_{T}^{1.2}}{H_{s}^{1.6}}
$$

which agrees closely with Equation 1 and Figure 3 (the average deviation is $20 \%$ ). The dependency on the bed diameter is stronger in Equation 2, represented by the power of 1.2.

These results illustrate that the concept of the model description and the corresponding empirical correlation, can both adequately describe measured entropy data from a wide range of operating conditions. This will now be further investigated.

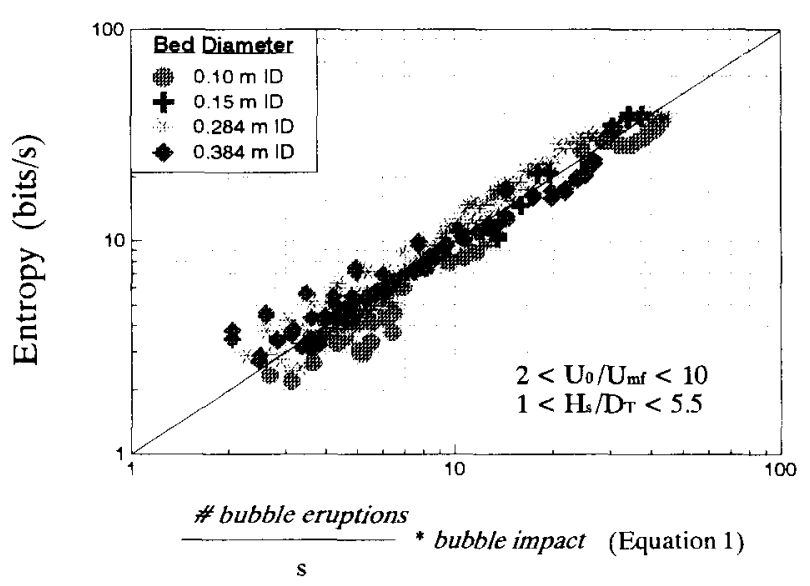

Figure 3: Correlation between measured entropies and the model correlation of Equation 1 (data of $0.56 \mathrm{~mm}$ polystyrene particles, Table 1; constants of Equation 1 are used).

Optimally, of course, direct validation of the concept of entropy being proportional to number of bubbles per second times bubble impact, is preferred, for example using tomographic measurements which give the time-dependent radial distribution of voidage at some axial measurement position. In this way, the local bubble properties can be directly and independently measured and compared to entropy data that are calculated simultaneously from the measured voidage or pressure fluctuations. This is presently being investigated at DUT (Kühn et al., 1995). For the moment, in this paper, bubble behavior is predicted as good as possible from well-known (empirical) literature correlations. It will now be shown how this concept applies to other experimental results from different operating conditions, particle systems, bed diameters, and from other measurement positions. It will be shown that deviations between measurements and predictions can very well be explained by shortcomings in the predictive capabilities of the empirical correlations that are used in the model as given by Equation 1.

Data at low gas velocities and in shallow beds $(0.56 \mathrm{~mm}$ polystyrene)

In Figure 4, data are shown at low gas velocities and/or at low aspect ratios, which are outside the ranges of practical fluidized bed operation conditions as used in Figure 3. Clearly, these data deviate considerably from both the empirical (Eq. 2) and the model (Eq. 1) descriptions. The (relative) deviation is larger for lower aspect ratios and increases for higher gas velocities. Near minimum fluidization, the measured entropy is always higher than predicted from Equation 2. Possible explanations for these observations will now be discussed. 
a) Shallow bed data

The predicted values for the entropy are higher than the measured values. A good fit, similar to Equation 2, could not be found. The most obvious explanations for deviations between data and model do not seem to apply here. For example, (i) not all excess gas forms bubbles: this would imply that $\phi \sim 0.2$ (Equation 1), which is too low for this type of particles, and, moreover, $\phi$ would depend on the aspect ratio, which is also not expected ( $c f$. Kunii and Levenspiel, 1991), or (ii) the distributor has an effect (especially for shallow bed data): however, from previous work (see e.g. Vander Stappen et al., 1993b), it was found that at the distributor the entropy typically increases, which is opposite to the trends observed here.

More likely, deviations are caused by other effects: $(i)$ the pressure probe does not 'sense' all bubbles (i.e. effective bed diameter $<D_{\mathrm{T}}$ ), at least not with the same impact (for all or only some fraction of the bubbles), and/or (ii) the actual bubbles are larger than predicted. Additional evidence for the second effect is that calculated estimates for the initial bubble sizes (near the distributor) are often larger than $D_{\mathrm{B}}$, as calculated here. On the other hand, when bubbles are large enough relative to the actual bed diameter, all bubbles will still be 'sensed' and the result of Figure 3 is obtained.

\section{b) Data at low gas velocities}

These data are rather scattered and no obvious correlation between the deviations and, for example, bed height, gas velocity, or estimated bubble size was found. Fitting these data as in Equation 2 did not give useful results.

However, possible explanations for the deviations of the low gas velocity data can be found. Bubble sizes may very well be overpredicted in the model, when the values are compared to initial bubble size estimates. It is most likely that near minimum fluidization (for some of the data $U_{\mathrm{e}}$ is only about $0.01 \mathrm{~m} / \mathrm{s}$ ), the higher irregularity of the bubble behavior (hence higher entropy) is important. Actually, the bed is more in a transition-like state than in a freely-bubbling state ( $c f$. Vander Stappen et al., 1993a). Also, turbulence (higher entropy) of the dense phase gas flow is relatively more important at lower gas velocities (assuming $U_{\mathrm{df}}$ remains at about $U_{\mathrm{m} f}$ independent of the gas velocity).

\section{A direct comparison between two different particle systems: polystyrene and sand (see Table I)}

Measurements as described above have also been done for $0.4 \mathrm{~mm}$ sand particles at the same probe positions and operating conditions. The measured values of $U_{\mathrm{mf}}$ are the same for the sand and polystyrene particles, while basically all other physical and mechanical properties (e.g. coefficient of restitution, friction factor) most probably will be different. The same value for $U_{\mathrm{m} f}$ means that the predictions of entropy from Equations 1 and 2 for the polystyrene and sand data are the same at the same operating conditions. However, it appears that measured entropies are different as can be observed from Figure 5a.

The measured entropies for sand typically are lower than the prediction of Equation 2; the deviation is up to $30 \%$ (based on Equation 1 this implies a bubble size which would be approximately $20 \%$ larger). On the average, the dependence of entropy on gas velocity is less strong for sand, which explains that the differences between both particle systems increase for larger bubbles (higher gas velocities). The small effect of the gas flow is clearly observed from a fit, analogously to Equation 2, for the sand data alone, which fits the sand data somewhat better on the average (see Figure $5 b$ ):

$$
K(b i t s / s)=11.1\left(U_{0}-U_{m f}\right)^{-0.06} \frac{D_{T}^{1.1}}{H_{s}^{1.6}}
$$

In terms of the model description of Equation 1, the result from Equation 3 would suggest that for the sand $D_{B} \propto U_{e}^{0.5}$; this power of 0.5 is still a typical value which is also found in other bubble size equations (e.g. by Rowe, 1976). Bubble sizes were not measured independently to verify the above assumption. However, interpretation of main frequencies and magnitudes of the pressure fluctuations also suggests that bubbles are larger 
for the sand. The measured average bed expansions (determined from the pressure drop) are about similar for both particle systems, which suggests that the total bubble holdup in the bed is the same; in other words, there are fewer but larger bubbles in the bed of sand compared to the bed of polystyrene particles.

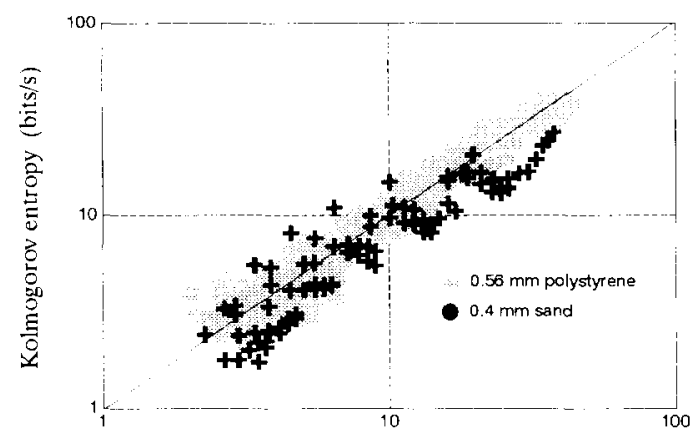

Fit from Equation 2

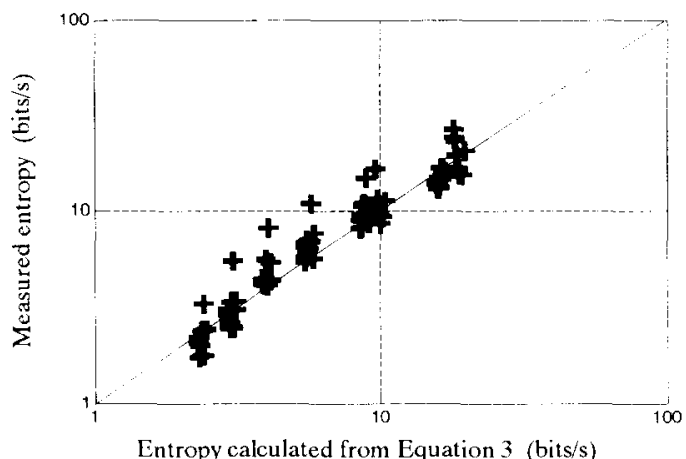

Entropy calculated from Equation 3 (bits/s)

Figure 5: Comparison between measured entropy of sand particles (see Table 1) and entropy calculated from Equation 2 (fitted for polystyrene particles; a: left figure), and entropy calculated from Equation 3 (fitted for sand particles; $b$; right figure).

Relatively small differences in the bubble sizes thus can explain the differences between the measured entropies of both particle systems. The differences in bubble size are not expected a priori because the (measured) values of the minimum fluidization velocity are the same. However, all other material properties of both particle systems are most probably different, which can have an (yet unknown) effect on the hydrodynamics and hence the entropy. For example, (i) the sphericity of the particles that influences the bubble shape, (ii) the particle density that influences the inertia and, possibly, (iii) dampening characteristics of the dense phase, and (iv) the particle size (distribution). The sphericity, density, and dimensionless size distribution are taken into account in the dimensionless similarity groups for fluidized beds as developed by Glicksman and coworkers (Glicksman et al., 1994). The particle density becomes more important in the so-called inertial limit (i.e. higher Reynolds numbers or bubble sizes), which qualitatively explains that the differences between sand and polystyrene increase for larger gas velocities.

Data measured at the wall of the bed $(0.56 \mathrm{~mm}$ polystyrene particles $)$

From the section on 'detection of bubble flow patterns' it is clear that the entropy can depend on the position of the measurement probe, especially when the bubbles are relatively small. Overall, it is found that, for relative bubble sizes $D_{\mathrm{B}} / D_{\mathrm{T}}>0.4$, the influence of the radial probe position is not strong. Previous discussions also indicated already that a pressure probe may not always measure all bubbles across the whole bed, at least not with the same strength (impact).

So far, correlations between entropy and fluidization parameters have been restricted to data from the centre of the bed. At the wall of the bed, the bubbles that rise near the wall will have the largest influence on the measured entropy. The effect of bubbles at, for example, the wall at the opposite side of the bed will possibly be very limited.

The differences between entropies measured with wall and centre probes are visualized in Figure 6, where wall data for the $0.56 \mathrm{~mm}$ polystyrene particles are plotted against the fit for the data in the centre of the bed (Equation 2). As expected, for the

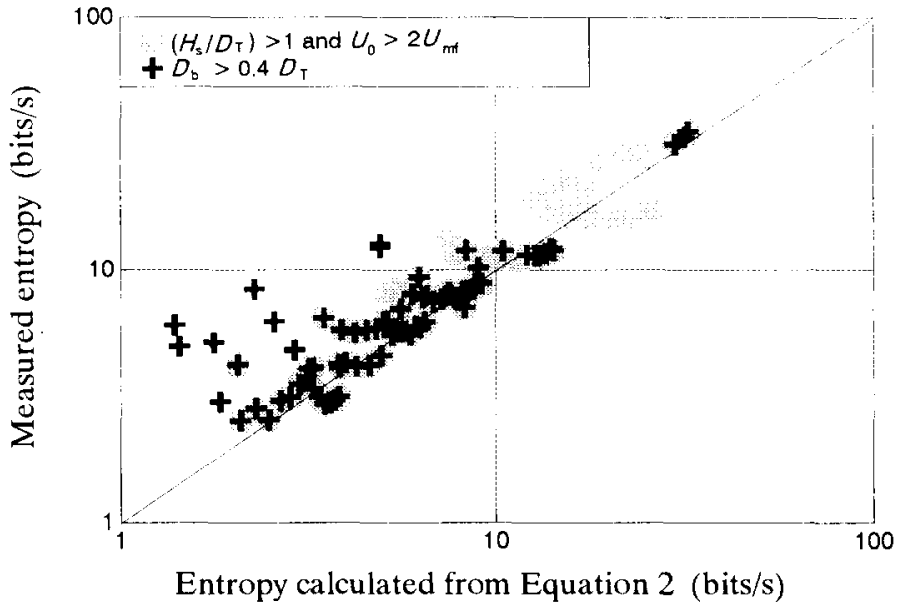

Figure 6: Correlation between measured entropy at the wall of the bed and entropy calculated from Equation 2. conditions where bubbles are large $\left(D_{\mathrm{B}}>0.4 D_{\mathrm{T}}\right)$ somewhat better agreement is observed than for smaller bubble sizes. However, this is not true for low gas velocities but large bubbles (i.e. high bed heights). 
Typically, the influence of the excess gas velocity is less strong for the wall data compared to the centre data. This is clear from an empirical fit, similar to Equation 2, for the wall data: $K=16.5\left(U_{0}-U_{m f}\right)^{0.04} D_{T}^{1.1} H_{s}^{-1.5}$. Again, data for which $H_{\mathrm{s}} / D_{\mathrm{T}}<1$ and $U_{0} / U_{\mathrm{mf}}<2$ are not included in this fit. The power for the dependence on $U_{\mathrm{v}}$ is negligibly small, but the powers for the dependence on the bed height and diameter are practically the same as for the data from the centre of the bed. A plot similar to Figure $5 \mathrm{~b}$ is obtained.

Wall data from various particle systems: improved model description

For other particle systems than the polystyrene and sand mentioned so far (Table 1), only measurements at the wall have been done. Therefore a direct comparison to Equation 2 is not possible. When the result for the polystyrene particles is assumed to hold for any particle system, a tentative comparison is possible for those situations where the calculated bubble size is above $40 \%$ of the bed diameter. An investigation of data from various particle systems revealed that correspondence only could be obtained when in the correlation the value of $U_{\text {mf }}$ is taken into account. The best fit was obtained for $U_{m f}^{-0.4}$, or (see Figure 7):

$$
K(\text { bits } / s)=10.7\left(\frac{U_{0}-U_{m f}}{U_{m f}}\right)^{0.4} \frac{D_{T}^{1.2}}{H_{s}^{1.6}}
$$

The agreement with data from various particle systems $\left(0.06<U_{\mathrm{mf}}<0.6 \mathrm{~m} / \mathrm{s}\right)$ and bed diameters is quite good.

Obviously, when data from different particle systems are considered, the dense phase properties have to be taken into account. It is suggested here to include therefore the Froude number of the dense phase at minimum fluidizing conditions, $F r=U_{m f}^{2} /\left(g D_{T}\right)$, which characterizes the ratio of intertial to gravity forces on the bed mass. The including of the Froude number can be explained as follows: ( $i$ ) larger inertia ( $F r$ larger) will lower the entropy as the effect of a bubble is more 'damped' by the mass of the bed, and (ii) larger gravitational forces ( $F r$ smaller) will increase entropy as the impact of a bubble on the pressure fluctuations is more pronounced. Agreement between this improved model description and the fit of Equation 4 is obtained when the power for the Froude number dependence is -0.2 :

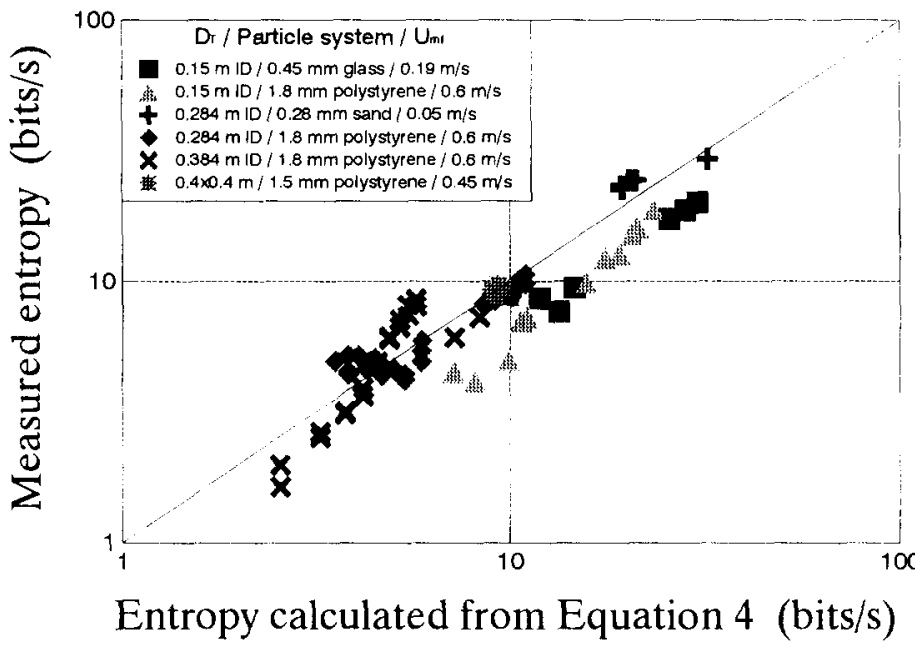

Figure 7: Comparison of measured entropy from different particle systems and bed diameters to entropy calculated from Equation 4: entropies were measured at the wall and at settled bed height; only those entropies are included for which the calculated. relative bubble size $D_{\mathrm{B}} / D_{\mathrm{T}}>0.4$. The legend denotes the bed diameter, particle system and value of $U_{\text {mf }}$

$$
K(\text { bits } / s) \propto N \frac{\pi}{4} D_{T}^{2}\left(\frac{D_{B}}{D_{T}}\right) F r^{-0.2} \propto\left(\frac{U_{0}-U_{m f}}{U_{m f}}\right)^{0.4} \frac{D_{T}^{1.2}}{H_{s}^{1.6}}
$$

The constant of proportionality depends on whether the same constant for the bubble size equation as in Equation 1 is used; if done so, the proportionality constant in Equation 5 is 0.35.

\section{DIMENSIONLESS SCALE-UP OF CHAOTIC DYNAMICS}

Firm understanding of the hydrodynamical behavior is crucial for a reliable scale-up of fluidized beds. It has been shown that chaos analysis provides a useful characterization of the complex hydrodynamical behavior and thus can be applied, for example, to assess the dynamical similarity between two (scaled) fluidized beds. Furthermore, it was shown how entropy depends on main bubbling bed design parameters, viz. (i) fluidization conditions (superficial gas velocity, settled bed height), (ii) particle properties $\left(U_{\mathrm{mf}}\right)$ and $(i i i)$ bed size (diameter). These two aspects form the core of what is being developed at DUT as a chaos scale-up methodology.

The question then rises how entropy should be scaled between differently sized beds in order to have dynamical similarity. Van den Bleek and Schouten (1993a) proposed as a first suggestion to keep the information flow per dimensionless time unit constant. In their article, they suggested, without experimental evidence, to normalize the time scales in a fluidized bed on $d_{\mathrm{p}} / U_{0}$, in accordance with a set of dimensionless scaling rules as developed by 
Glicksman (1984). More recently, Glicksman et al. (1994) proposed a new (simplified) set of scaling rules according to which the fluidized bed time scales are proportional to $H_{s} / U_{0}$ or $\sqrt{m}$, where the scaling factor $m$ is the ratio of the bed diameters of the large and small bed. The similarities in the chaotic behavior between two beds, scaled according to this simplified set of scaling rules, have been investigated at DUT and are reported elsewhere (Vander Stappen, 1996). The main result, relevant to this paper, is that indeed it is measured that entropy remains constant when using $\sqrt{m}$ to normalize the time scale. In other words, the rate of information loss at the large scale is similar to that at the small scale, as suggested by Van den Bleek and Schouten (1993a).

Interestingly, it is found that when the set of operating parameters, as it is calculated from Glicksman's rules are used in Equation 5, the entropy as it is predicted from that Equation scales with a factor of $m^{-0.4}$ between the small and the large bed, which is close to $m^{-0.5}$. This can be considered to be within the margins of accuracy of the correlations that are used. This near-consistency between two completely different scaling methods confirms the scaling concept of the entropy model in Equation 5.

\section{Numerical examples of use of entropy correlations for scale-up}

Using the entropy correlations for scale-up, operating conditions can be chosen such that the entropy has some desired value at a given bed diameter. A numerical example was given in Vander Stappen et al. (1995) for constant entropy (in bits/s) at different bed diameters. The discussion above results in $K \propto 1 / \sqrt{m}$. In a practical situation, the desired value of entropy on the large scale will depend on what is considered as the most important aspect to scale (e.g. bubble size, rate of mass transfer, chemical conversion, avoiding elutriation, mixing, et cetera). For example Werther (1992) shows that mass transfer, and thus conversion, of a catalytic reaction may be much lower in the large bed than in the small one, which confirms the need for a proper scaling of the bubbling hydrodynamics. In this paper no attempt will be made in explaining how entropy is related to overall reactor performance. In Figure 8 an example is shown of using the entropy correlation in this paper (Equation 5) for the sole scale-up of the chaotic dynamics. For comparison, operating conditions have been calculated for which the entropy is the same, as well as for which it is scaled with $1 / \sqrt{m}$. In a next paper, the issue of chaotic similarity and overall reactor performance will be further addressed (Schouten and Van den Bleek, 1996).
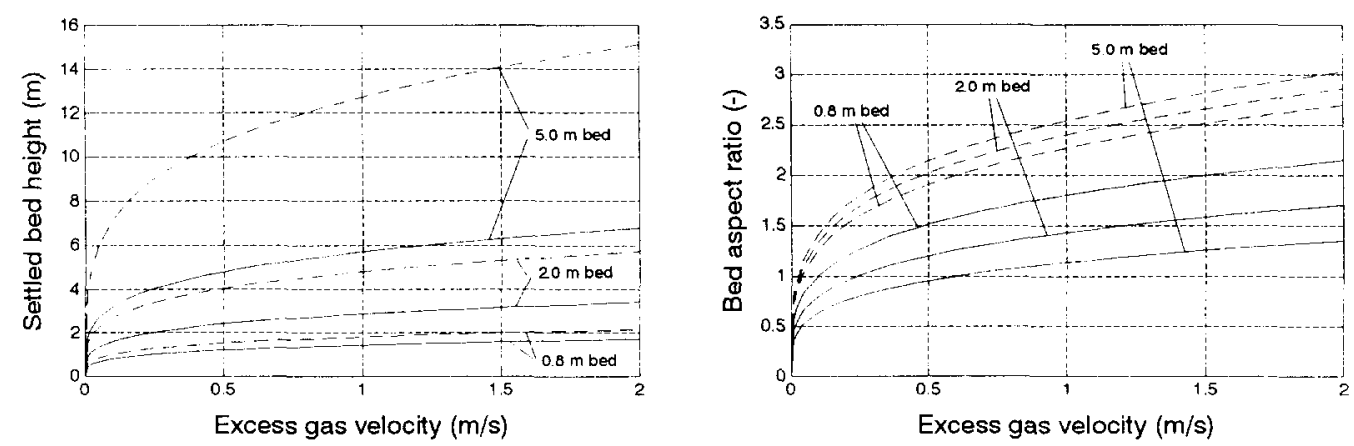

Figure 8: Illustration of the use of Equation 5 for scale-up of the chaotic hydrodynamics a $0.384 \mathrm{~m}$ ID bubbling fluidized bed $\left(H_{s}\right.$ $=0.62 \mathrm{~m}$ and $U_{0}=0.45 \mathrm{~m} / \mathrm{s} ; 0.56 \mathrm{~mm}$ polystyrene particles, see Table 1) to three larger scale beds of $0.8,2.0$ and $5.0 \mathrm{~m}$ ID; solid lines - constant entropy of $10 \mathrm{bits} / \mathrm{s} ;$ dashed lines - entropy $\propto \sqrt{m}$.

Clearly, bed height and gas velocity can be chosen independently to obtain the desired entropy for a wide range of operating conditions. A higher gas velocity requires a larger bed height as well. The bed height increases less than proportional with the bed diameter when to keep the entropy constant.

\section{CONCLUDING REMARKS}

- An important criticism of the chaos scale-up methodology presented here is that it is strongly based on empirical data, and thus its predictive capacity is limited to bed sizes only that belong to the range of 0.1 to $0.8 \mathrm{~m}$ ID as is investigated in this paper. This immediately calls for the need of a measurement of entropy in a (much) larger bed of even a few meters in diameter. It can thus very quickly be evaluated whether the correlation of Equation 5 also holds up to this (much) larger scale. Of course, this means that a measurement should be done in an industrial bubbling fluidized reactor, which might not be easy but certainly very worthwhile.

- Investigation of the validity range of the correlations presented here should, of course, not be limited to the bed size only. Also, it has to be verified whether the criteria for the bed aspect ratio and the superficial gas velocity (as shown in Figure 3) will still hold at the larger bed sizes as well. Possibly, a better and more refined description can be obtained by describing the shallow bed data (viz. small-bubble data) of Figure 4 separately. This latter issue may be of considerable importance for industrial practice where bed aspect ratios $\left(H_{\mathrm{s}} / D_{\mathrm{T}}\right)$ much larger than 2 may be not very common. 
- Most probably, it will be important to find similar correlations for entropies measured at the wall of bubbling beds, because wall measurements will be more readily available, especially in larger beds (of commercial size).

- The following step in this study is to relate the chaotic fluidized bed dynamics to mass transfer and reactor chemical performance (Schouten and Van den Bleek, 1996).

\section{NOTATION}

$\bar{d}_{p} \quad$ average diameter

$\mathrm{d}_{\mathrm{xx}} \quad \mathrm{xx} \%$ percentile

$\mathrm{D}_{\mathrm{T}}$ bed diameter

$\mathrm{D}_{\mathrm{B}}$ bubble diameter

Fr Froude number

\author{
$\mathrm{H}_{\mathrm{s}}$ settled bed height \\ $\mathrm{K}$ entropy \\ $\mathrm{N}$ number of bubbles per unit \\ area and unit time \\ $\phi$ fraction bubble gas
}

$\begin{array}{ll}\rho_{\mathrm{p}} & \text { density } \\ \mathrm{U}_{0} & \text { gas velocity } \\ \mathrm{U}_{\mathrm{mf}} & \text { minimum fluidization } \\ & \text { velocity } \\ \mathrm{V}_{\mathrm{B}} & \text { bubble volume }\end{array}$

\section{ACKNOWLEDGEMENTS}

The authors are grateful to Professor F. Takens for his assistance in the development of the method to calculate the Kolmogorov entropy from measured time series as well as for the valuable discussions about the interpretation of the experimental results. This work is supported in part by the Research stimulus fund of DUT and in part by DSM.

\section{REFERENCES}

Bouillard, J.X. and Miller, A.L., 1994, Powder Techn., 79, 211.

Darton, R.C., LaNauze, R.D., Davidson J.F. and Harrison, D., 1977, Trans. I. Chem. E., 55, 274.

Daw, C.S. and Halow, J.S., 1991, Proc. 11th Int. Conf. on FBC, Vol. 1 (Ed. E.J. Anthony), p. 777.

Daw, C.S. and Halow, J.S., 1992, AIChE Symposium Series, 88, 61.

Daw, C.S. and Halow, J.S., 1993, AIChE Symp. Ser., 89, 103.

Daw, C.S. Lawkins, W.F., Downing, D.J. and Clapp Jr., N.E., 1990, Phys. Rev. A, 41, 1179.

De Korte, R.J., Schouten, J.C. and Van den Bleek, C.M., 1995, Phys. Rev. E, 52, 3358.

Fuller, T.A., Flynn, T.J., Daw, C.S. and Halow, J.S., 1993, Proc. 12th Int. Conf. on FBC, Vol. 1, p. 141.

Glicksman, L.R., 1984, Chem. Engng Sci., 39, 1373.

Glicksilian, L.R., Hyre, M.R. and Farell, P.A., 1994, Int. J. Multiphase Flow, 20, Suppl., 331.

Halow, J.S. and Daw, C.S., 1994, AIChE Symp. Ser., 90, 69.

Hay, J.M., Nelson, B.H., Briens, C.L. and Bergougnou, M.A., 1995, Chem. Engng Sci., $50,373$.

Hilborn, R.C., 1994, Chaos and nonlinear dynamics, Oxford University Press.

Kühn, F.T., Schouten, J.C., Mudde, R.F., Van den Bleek, C.M. and Scarlett, B., 1996, Measurement Science and Technology (in press).

Kunii, D., and Levenspiel, O., 1991, Fluidization Engineering, Butterworth-Heinemann, Boston, USA.

Moon, F.C., 1992, Chaotic and fractal dynamics, John Wiley and Sons, Inc., New York, USA.

Ott, E., Grebogi, C. and Yorke, J.A., 1991, Phys. Rev. Lett., 64, 1196.

Rowe, P.N., 1976, Chem. Engng Sci, 31, 285.

Schouten, J.C., and Van den Bleek, C.M., 1991, Proc. Ilth Int. Conf. on FBC, Vol. 1, p. 459.

Schouten, J.C., and Van den Bleek, C.M., 1992, AIChE Symp. Ser., 88, 70.

Schouten, J.C., and Van den Bleek, C.M., 1996, in preparation for submission.

Schouten, J.C., Van der Stappen, M.L.M. and Van den Bleek, C.M., 1992, Fluidization VII, p. 103.

Schouten, J.C., Takens, F. and Van den Bleek, C.M.. 1994a, Phys. Rev. E, 49, 126.

Schouten, J.C., Takens, F. and Van den Bleek, C.M., 1994b, Phys. Rev. E, 50, 1851.

Skrzycke, D.P., Nguyen, K. and Daw, C.S., 1993, Proc. 12th Int. Conf. on FBC. Vol. 1, p. 155.

Stringer, J., 1989, Proc. 10th Int. Conf. on FBC, Vol. 1, pp. 265-272.

Takens, F., 1981, Lecture Notes in mathematics, 898, 366.

Van den Bleek, C.M. and Schouten, J.C., 1993a, Chem. Engng Sci., 48, 2367.

Van den Bleek, C.M. and Schouten, J.C., 1993b, Chem. Eng. J., 53, 75.

Vander Stappen, M.L.M., 1996, PhD thesis, Delft University of Technology.

Vander Stappen, M.L.M., Schouten, J.C. and Van den Bleek, C.M., 1993a, AIChE Symp. Ser., 89, 91.

Vander Stappen, M.L.M., Schouten, J.C. and Van den Bleek, C.M., 1993b, Proc. 12th Int. Conf. on FBC, Vol. 1, p. 129.

Vander Stappen, M.L.M., Schouten, J.C. and Van den Bleek, C.M., 1993c, Proc. 4th Intern. Confer. on Circulating Fluidized Beds, Somerset. PA, USA, p. 54.

Vander Stappen, M.L.M., Schouten, J.C. and Van den Bleek, C.M., 1994, Preprints 1st Particle Technology Forum, Part I, p. 446.

Vander Stappen, M.L.M., Schouten, J.C. and Van den Bleek, C.M., 1995, Fluidization VIII, Vol. 1, p.625.

Vasudevan, M., Finney, C.E.A., Nguyen, K., Van Goor, N.A., Bruns, D.D. and Daw, C.S., 1995, Proc. 13th Int. Conf. on FBC, Vol. 2, p. 1001.

Werther, J., 1992, Chem. Engng Sci., 47, 2457. 